\title{
Prenatal Choline Supplementation Protects against Postnatal Neurotoxicity
}

\author{
Shirley X. Guo-Ross, ${ }^{1,3}$ Suzanne Clark, ${ }^{1,2}$ Daniel A. C. Montoya, ${ }^{1,3}$ Katherine H. Jones, ${ }^{1,2}$ Jennifer Obernier, ${ }^{6}$ \\ Ashok K. Shetty,,$^{1,4}$ Aaron M. White, ${ }^{1,3}$ Jan Krzysztof Blusztajn, ${ }^{7}$ Wilkie A. Wilson, ${ }^{1,2}$ and \\ H. Scott Swartzwelder ${ }^{1,3,5}$
}

${ }^{1}$ Neurobiology Research Laboratory, Veterans Affairs Medical Center, Durham, North Carolina 27705, Departments of ${ }^{2}$ Pharmacology, ${ }^{3}$ Psychiatry, and ${ }^{4}$ Surgery, Duke University Medical Center, Durham, North Carolina 27710, ${ }^{5}$ Department of Psychology, Duke University, Durham, North Carolina 27710, ${ }^{6}$ Center for Alcohol Studies, University of North Carolina School of Medicine, Chapel Hill, North Carolina 27514, and ${ }^{7}$ Department of Pathology and Laboratory Medicine, Boston University School of Medicine, Boston, Massachusetts 02118

Choline, a dietary compound present in many foods, has recently been classified as an essential nutrient for humans. There is evidence from animal models that the availability of choline during the prenatal period influences neural and cognitive development. Here we report that choline supplementation during a $6 \mathrm{~d}$ gestational period protects against neurodegeneration in the posterior cingulate and retrosplenial cortices of female adolescent rats produced by peripheral administration of the NMDA receptor antagonist dizocilpine (MK-801). These data show that availability of a single nutrient, choline, during a brief period of prenatal development diminishes vulnerability to neurotoxicity in adolescent offspring.

Key words: choline; neurotoxicity; cingulate; NMDA; MK-801; supplementation
Poor nutrition early in life, as well as perinatal insults such as exposure to alcohol or other neurotoxins, have been linked to a variety of abnormalities in brain development and behavior. Thus, there is much interest in ensuring that pregnant and lactating women consume a diet that is rich in nutrients necessary for the proper physical and cognitive development of children. An example is the recent public health policy initiative in the United States designed to reduce the incidence of neural tube defects in newborns by supplementing all grain products with folic acid to ensure high folate consumption by American women.

Choline, although less well studied than folate, is also an essential nutrient. In recognition of its key role during development, the recommended daily intake of this compound is higher during pregnancy and lactation (Zeisel and Blusztajn, 1994; Blusztajn, 1998). Although choline is available in many foods, the normal dietary sources may prove to be insufficient during times of heightened need, such as pregnancy and lactation (Zeisel and Blusztajn, 1994). Because choline is particularly important during fetal development, dietary supplementation during this time could provide long-lasting benefits.

Recent studies in animal models have indicated that prenatal choline supplementation does indeed produce enduring enhancements of CNS function. For example, prenatal choline supplementation has been shown to increase phospholipase-D activity in the hippocampus of adult offspring (Holler et al., 1996) and to decrease acetylcholine esterase activity in the hippocampus of

\footnotetext{
Received July 11, 2001; revised Sept. 21, 2001; accepted Oct. 9, 2001.
}

This research was supported in part by National Institute on Aging Grant P01AG09525 to H.S.S. and by Senior Veterans Affairs Research Career Scientist Awards to H.S.S. and W.A.W. We extend our thanks to Dr. Vandana Zaman for her expertise and advice with respect to histological methods.

Correspondence should be addressed to Dr. H. Scott Swartzwelder, Veterans Affairs Medical Center, 508 Fulton Street, Building 16, Room 24 (151E), Durham, NC 27705. E-mail: hss@duke.edu.

Copyright (C) 2001 Society for Neuroscience $\quad 0270-6474 / 01 / 220001-06 \$ 15.00 / 0$ juvenile offspring (Cermak et al., 1999). These changes are consistent with the improvements in spatial (Meck et al., 1988; Williams et al., 1998) and temporal (Meck and Williams, 1997) memory observed in adult offspring after prenatal choline supplementation, as well as with enhancement of NMDA receptormediated neurotransmission (Montoya and Swartzwelder, 2000) and long-term potentiation (Pyapali et al., 1998) in hippocampal slices from prenatally choline-supplemented rats.

Prenatal choline supplementation has also been shown to protect against the memory deficits that occur after severe pilocarpine-induced seizures (Yang et al., 2000). This finding suggests that prenatal choline supplementation may provide protection against postnatal neurotoxicity. Because of our interest in neurotoxicity from drugs of abuse, we were interested in whether this supplementation could protect against the neurotoxicity in the cingulate gyrus produced by NMDA receptor antagonists, several of which are drugs of abuse, including ethanol, ketamine, and phencyclidine. To test this hypothesis, we provided dietary choline supplementation to pregnant rat dams during a $6 \mathrm{~d}$ period and then measured the neurotoxic effect of the NMDA receptor antagonist dizocilpine (MK-801) on the offspring during adolescence.

This article is published in The Journal of Neuroscience, Rapid Communications Section, which publishes brief, peerreviewed papers online, not in print. Rapid Communications are posted online approximately one month earlier than they would appear if printed. They are listed in the Table of Contents of the next open issue of JNeurosci. Cite this article as: JNeurosci, 2002, 22:RC195 (1-6). The publication date is the date of posting online at www.jneurosci.org.

http://www.jneurosci.org/cgi/content/full/5942 


\section{MATERIALS AND METHODS}

Prenatal choline treatment. Pregnant Sprague Dawley rats were obtained from Charles River (Raleigh, NC) at day 9 of gestation [embryonic day 9 (E9)] and housed individually in clear polycarbonate cages $(27.9 \times$ $27.9 \times 17.8 \mathrm{~cm}^{3}$ ) on a $12 \mathrm{hr}$ light/dark cycle at the Durham Veterans Affairs Medical Center vivarium. From the day of arrival, dams were given tap water and purified Dyets formula AIN-76A (Dyets Inc., Bethlehem, PA) containing the standard amount of choline $(7.9 \mathrm{mmol} / \mathrm{kg}$ choline chloride) ad libitum. This provided an average daily choline intake of $\sim 1.3 \mathrm{mmol} / \mathrm{kg}$. During E12-E17, choline chloride $(25 \mathrm{~mm})$ supplemented drinking water was given to one group of dams ("supplemented"). The other group was given water with no added choline ("nonsupplemented"). The average total water intake across days E12E17 was $158 \mathrm{gm}$ for control dams and $149 \mathrm{gm}$ for those receiving choline supplementation. This resulted in an average daily choline intake of 4.6 $\mathrm{mmol} / \mathrm{kg}$ for the supplemented group, whereas the nonsupplemented group continued to receive the standard amount $\left(1.3 \mathrm{mmol} \cdot \mathrm{kg}^{-1} \cdot \mathrm{d}^{-1}\right)$. In both groups, saccharine $(50 \mathrm{~mm})$ was used to neutralize the bitter taste of choline in the water and to equalize intake among dams in the treatment groups. The E12-E17 time frame was chosen because it is a critical period during which manipulation of dietary choline results in both behavioral (Meck et al., 1988; Meck and Williams, 1997; Williams et al., 1998) and electrophysiological (Pyapali et al., 1998; Montoya and Swartzwelder, 2000) changes in offspring.

After E17, all dams were placed back on regular tap water (i.e., without choline or saccharine) and continued on the normal AIN-76A diet. Within $24 \mathrm{hr}$ after birth, the pups were cross-fostered between the dams to litters of equal size ( $n=12-14 /$ litter). Pups were weaned at postnatal day 22 (P22), housed four to a cage, and provided the AIN-76A diet (i.e., with a standard choline level) and water ad libitum.

Drug treatment. A total of 16 male and 16 female offspring from a total of five litters were used for this study. One-half of the rats of each gender were given MK-801 $(5 \mathrm{mg} / \mathrm{kg}$, at $1 \mathrm{ml} / \mathrm{kg}$ injection volume, i.p.; RBISigma, St. Louis, MO) on P39, and the other one-half were administered MK-801 on P42. At the time of MK-801 injection, the average body weights (in grams) were 190 ( \pm 4 SEM, male, control), 180 ( \pm 3.2 SEM, male, supplemented), 141 ( \pm 6.2 SEM, female, control), and $137( \pm 3.7$ SEM, female, supplemented). This dose of MK-801 has been shown to produce neurotoxicity in young rats (Olney et al., 1991; Fix et al., 1995; Corso et al., 1997). Saline-injected controls were not used, because previous studies have shown that positive neurons are almost never seen with Fluoro-Jade (FJ) staining in saline-injected rats (Schmued et al., 1997). This was demonstrated clearly in a similar study designed to study the effects of agents that were protective against NMDA receptor antagonist-induced neurotoxicity (Olney et al., 1991).

Histology. At 3 days after MK-801 injection, the rats were weighed, anesthetized with Halothane, and perfused transcardially with $150 \mathrm{ml}$ of heparinized saline followed by $250 \mathrm{ml}$ of $4 \%$ paraformaldehyde. The brains were removed and post-fixed in $4 \%$ paraformaldehyde overnight, transferred to $0.1 \mathrm{M}$ phosphate buffer $(\mathrm{PB})$ for $1 \mathrm{~d}$, and then soaked in $30 \%$ sucrose in $0.1 \mathrm{M}$ PB for 3-5 d until sinking. Cryostat sections (40 $\mu \mathrm{m})$ were cut and stored in $0.1 \mathrm{M} \mathrm{PB}$ at $4^{\circ} \mathrm{C}$.

The sections were processed for staining with FJ-B or with the older, related fluorochrome, FJ. Sections from all of the animals were stained with FJ-B, and the cell numbers from these sections were used for all statistical analyses. Alternating sections from one-half of the animals from each treatment group were stained with FJ as an internal comparison of the methods and for purposes of illustration. The staining methods were as described previously (Schmued et al., 1997; Schmued and Hopkins, 2000). Both FJ and FJ-B provided similar staining patterns with respect to the anatomical regions stained, the number of positive neurons per region, and agreement between the individuals doing the counting. FJ provided better staining of neuronal processes, and so was used for photographic images (Fig. 1). FJ-B showed less background staining (and positive neurons stood out more clearly, facilitating counting), and so was used for quantitative measures. Twelve serial sections (approximately every seventh section) from each animal were selected in a rostral-tocaudal orientation and comprised $3.5 \mathrm{~mm}$ along the anteroposterior axis of the cingulate cortex (CC) and retrosplenial cortex (RSC) $(-0.3$ to $-3.8 \mathrm{~mm}$ from bregma; see Fig. $3 A, B)$. Sections were mounted from distilled water onto $0.5 \%$ gelatin-coated slides and air-dried at room temperature overnight. Slides were then processed in the following solutions: $100 \%$ ethanol $(3 \mathrm{~min}), 70 \%$ ethanol $(1 \mathrm{~min})$, distilled water $(1$ $\mathrm{min}), 0.06 \%$ potassium permanganate ( $7 \mathrm{~min}$ with slow shaking), distilled water $(1 \mathrm{~min}), 0.01 \% \mathrm{FJ}$ or $0.004 \%$ FJ-B (Histo-Chem Inc., Jefferson,
AR) (in $0.1 \%$ acetic acid) for $30 \mathrm{~min}(\mathrm{FJ})$ or $20 \mathrm{~min}$ (FJ-B) with slow shaking in the dark, and distilled water (three times for 1 min). Slides were then air-dried in the dark for at least $2 \mathrm{hr}$ (but not $>2 \mathrm{~d}$ ); dehydrated in 70, 95, and $100 \%$ ethanol; placed in xylene; and then coverslipped with distyrene plasticizer xylene (Electron Microscopy Sciences, Washington, PA).

The stained sections were examined with a Nikon (Tokyo, Japan) epifluorescence microscope using a FITC filter. Neurotoxicity was assessed by an individual who was blind to the treatment condition of the animals from which sections were taken. In the $\mathrm{CC}-\mathrm{RSC}$ region, bilateral FJ-positive cell counts were made from 12 serial sections (see Fig. 3).

Some FJ-stained sections (four each from supplemented and nonsupplemented animals) were counterstained with hematoxylin and eosin (H\&E) using standard methods (Fig. 1). Three measures of neurodegeneration were qualitatively assessed by visual inspection: nuclear size, condensation, and an eosinophilic cell body. Four sections per animal in both supplemented and nonsupplemented groups were also stained for neurodegeneration using a silver staining kit (FD NeuroTechnologies, Ellicott City, MD). Degenerating neurons were assessed under a light microscope (by visual inspection).

Statistical analysis. The data from FJ-positive cell counts were analyzed using a two-way ANOVA with dietary treatment condition and day of MK-801 administration as between-subjects factors and histological section as the within-subjects factor. Comparisons of particular histological sections across dietary treatment groups were made using parametric post hoc tests where appropriate and secondary to the overall ANOVA.

\section{RESULTS}

Consistent with previous findings, administration of MK-801 caused degeneration of neurons in the CC-RSC (Olney et al., 1989; 1991), as evidenced by FJ staining (Fig. 1A,B) (Schmued and Hopkins, 2000), and varied across the rostral-to-caudal sections that were analyzed (Fix et al., 1995; Corso et al., 1997).

As reported previously, females were more sensitive than males to NMDA receptor antagonist-induced neurotoxicity (Hönack and Löscher, 1993; Fix et al., 1995). Very little neuronal damage was observed in male offspring of either age. Of a total of 16 male rats tested, only 3 rats showed any FJ-positive stained neurons, and in those rats, the maximum number of stained neurons in any section was eight. The average number of positively stained neurons per section was $0.16( \pm 0.09$ SEM) in sections from control males, and $0.3( \pm 0.11$ SEM) in sections from prenatally choline-supplemented animals. This minimal amount of positive staining in sections from males precluded any statistical comparisons between control and choline-supplemented males. Therefore, all subsequent analyses were performed on females.

In FJ-stained sections, degenerating neurons have a bright yellowish-green soma against a dark green background. Some neurons were clearly pyramidal in shape, and in some neurons proximal processes were also stained. In the sections from control animals, $80 \%(\mathrm{SD}=2)$ of the FJ-positive neurons were pyramidal; in sections from prenatally choline-supplemented animals, $83 \%(\mathrm{SD}=4.5)$ were pyramidal. This difference was not statistically significant $\left(t_{(8)}=1.462 ; p=0.18\right)$. Neurodegeneration was most prominent in deep cortical layers, consistent with typical NMDA receptor antagonist-induced neurotoxicity, in which cortical layers III and IV are the most affected (Olney et al., 1989, 1991). To further confirm that FJ-positive neurons were indeed degenerating, we stained representative sections from supplemented and nonsupplemented female rats with two other widely used methods to assess neurodegeneration: $H \& E$ and silver. Some FJ-stained sections were also counterstained with H\&E (FJ plus $H \& E)$. In these sections, all FJ-positive neurons showed degeneration characterized by eosinophilic staining of the soma and proximal dendrites. Figure $1 C$ shows a FJ plus $H \& E$ counterstained section in two views (Fig. $1 C_{1}$, FJ; Fig. $1 C_{2}$, H\&E). As 

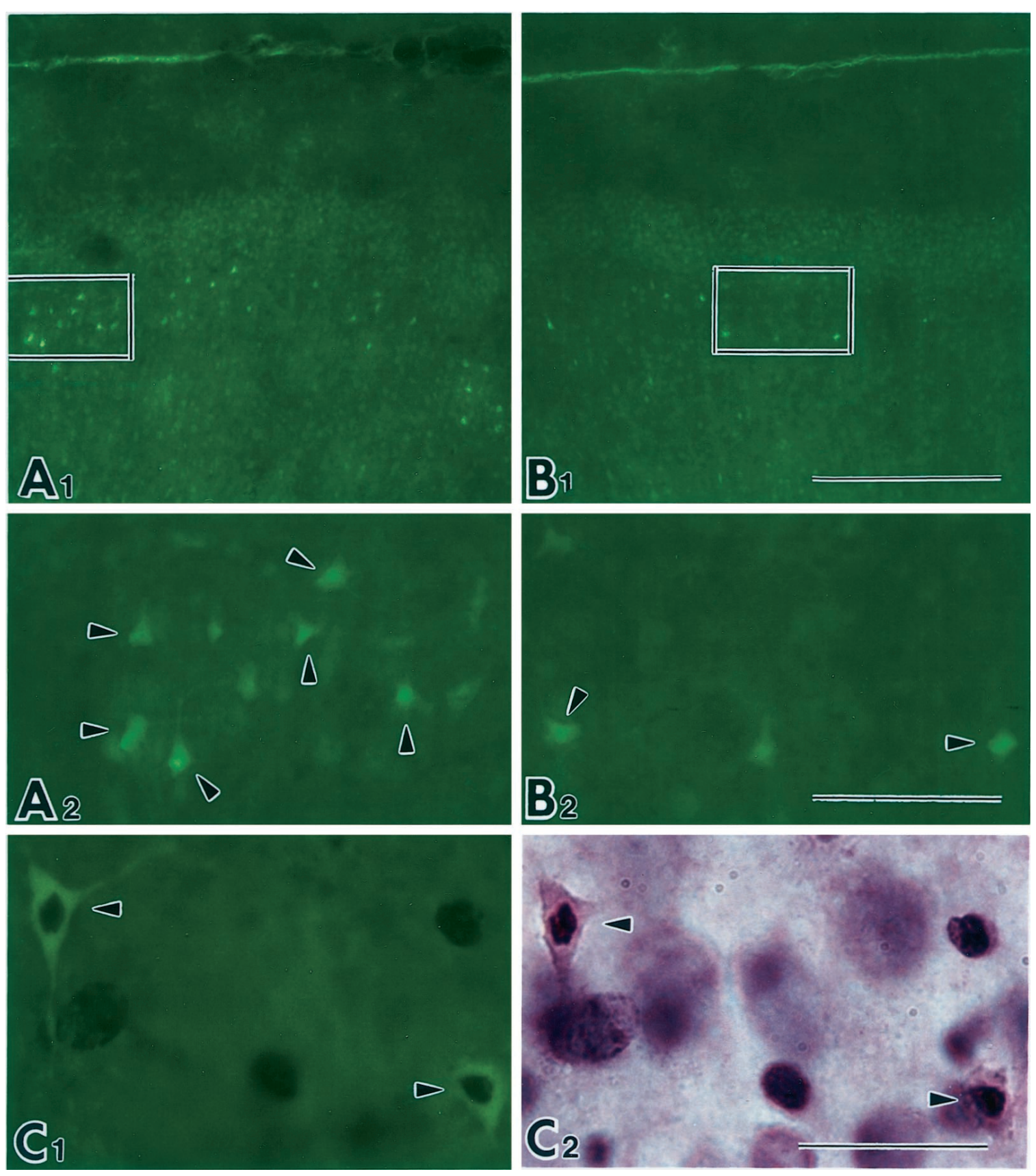

Figure 1. Fluoro-Jade staining of sections from MK-801-treated nonsupplemented $(A)$ and choline-supplemented $(B)$ female rats. $A_{1}$ and $B_{1}$ show a low-magnification view ( $10 \times$ magnification). Scale bar, $200 \mu \mathrm{m}$. Boxes in $A_{1}$ and $B_{1}$ indicate areas enlarged in $A_{2}$ and $B_{2}$ (40× magnification). Scale bar, $50 \mu \mathrm{m}$. $C$, Fluoro-Jade-positive stained neurons $\left(C_{7}\right)$ counterstained with H\&E $\left(C_{2}\right)$ : $(100 \times$ magnification). Scale bar, $20 \mu \mathrm{m}$. Arrowheads show degenerating neurons. Sections were taken from between approximately -2.00 and $-2.25 \mathrm{~mm}$ relative to bregma.

shown in Figure 2, silver staining revealed neurodegeneration in the same layers as FJ staining.

Prenatal choline supplementation provided significant protection against MK-801-mediated neurotoxicity in female rats. Figure $3 C$ shows the number of FJ-B-positive neurons in sections from choline-supplemented and nonsupplemented female animals that were treated with MK-801 on P39 (Fig. 3C, left) or P42 (Fig. 3C, right). The ANOVA revealed significant main effects for both dietary choline treatment $\left(F_{(1,12)}=17.33 ; p=0.001\right)$ and day of MK-801 treatment $\left(F_{(1,12)}=5.35 ; p=0.039\right)$. In addition, the number of FJ-B-positive neurons varied significantly across the 12 sections analyzed $\left(F_{(11)}=34.32 ; p<0.0009\right)$. There was a significant interaction between this effect and the main effect of dietary treatment $\left(F_{(11)}=6.98 ; p<0.0009\right)$, indicating that the effect of choline treatment varied with the rostrocaudal depth of the sections analyzed.

\section{DISCUSSION}

Dietary choline supplementation during gestation protected against MK-801-induced neurotoxicity in adolescent offspring. This finding is striking because it indicates that moderate dietary supplementation with an essential nutrient during a brief period of prenatal development produces an enduring neuroprotective 

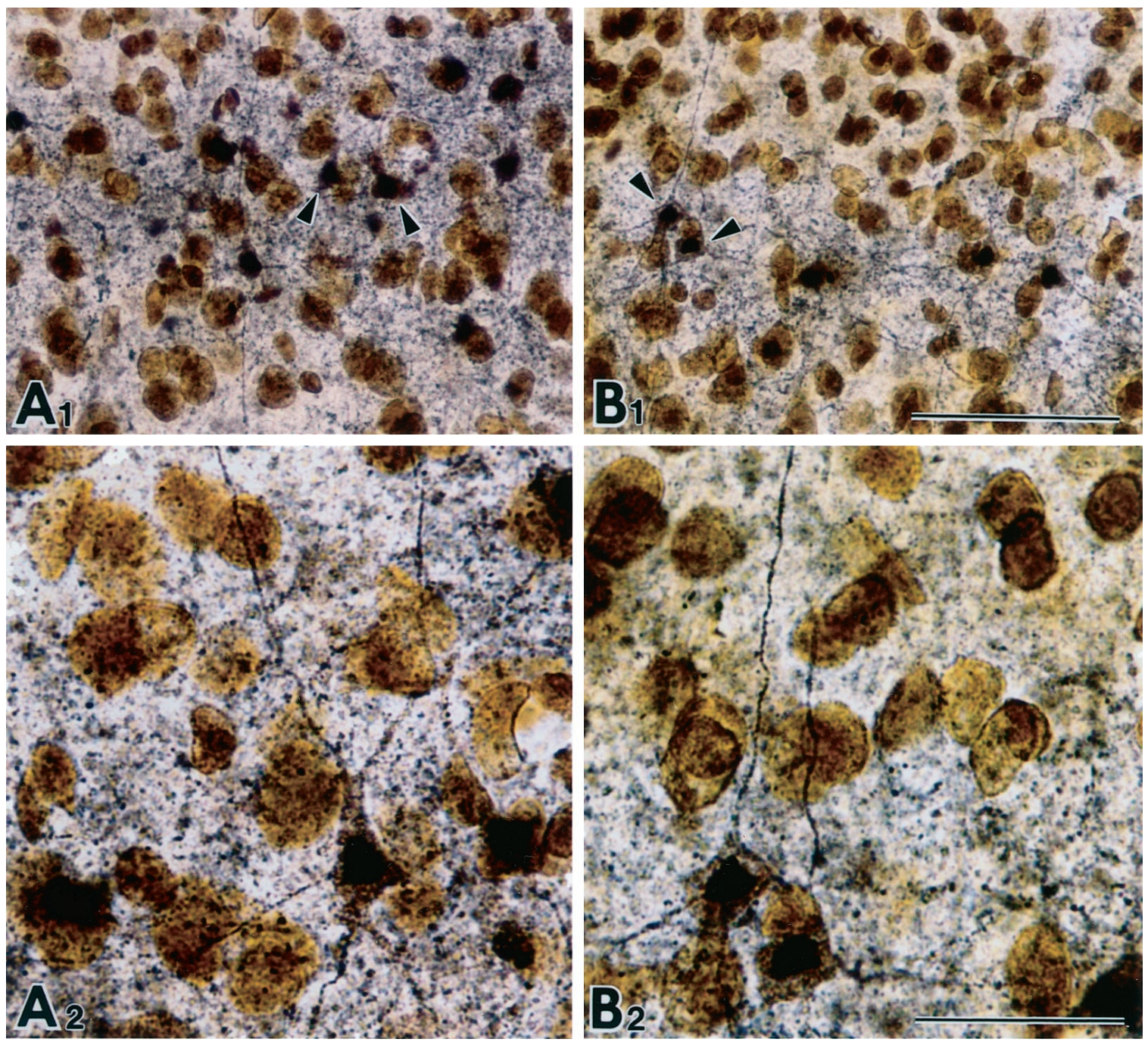

Figure 2. Illustration of silver staining of sections from MK-801-treated nonsupplemented $(A)$ and choline-supplemented $(B)$ female rats. $\left(A_{1}\right.$ and $B_{1}$ : $40 \times$ magnification). Scale bar, $50 \mu \mathrm{m}$. Arrowheads in $A_{1}$ and $B_{1}$ show the same degenerating neurons magnified in $A_{2}$ and $B_{2}$ (100× magnification). Scale bar, $20 \mu \mathrm{m}$. Sections were taken from between approximately -2.00 and $-2.25 \mathrm{~mm}$ relative to bregma.

effect on the offspring. This result is quite unique because most studies of prenatal dietary manipulations have focused on the negative outcomes of nutritional deficiency rather than on positive outcomes of supplementation.

The mechanisms underlying NMDA receptor antagonistinduced toxicity are not well understood. However, there is evidence from in vivo (Olney et al., 1991; Sharp et al., 1994, 2001; Tomitaka et al., 2000) and in vitro (Li et al., 2000) studies that inhibitory processes may be involved. Based on those findings, it has been proposed that NMDA receptor antagonists cause neurodegeneration by blocking NMDA receptor-mediated excitatory inputs onto inhibitory interneurons, and this could create a state of disinhibition sufficient to render the principle neurons vulnerable to excitotoxicity.

We do not know whether choline supplementation provides protection by directly opposing excitotoxicity or by indirectly interacting with modulatory processes. One possibility is that it does so through a cholinergic mechanism. Previous studies have shown that prenatal choline supplementation causes increased release of acetylcholine in offspring (Cermak et al., 1998), and stimulation of nicotinic cholinergic receptors is known to be neuroprotective against some neurotoxic processes (Belluardo et al., 2000). Perhaps supplemented animals activate more nicotinic receptors and are therefore protected against NMDA receptor antagonist toxicity. However, other studies have shown that NMDA receptor antagonist toxicity is reduced by muscarinic cholinergic antagonists. This would suggest that muscarinic receptors somehow mediate a toxic process. Prenatal choline supplementation could also act through more general mechanisms. For example, acetylcholine has morphogenetic actions during brain development (Lauder and Schambra, 1999), and thus could influence a number of processes that could prove to be neuroprotective. Clearly more studies are needed to adequately test these hypotheses.

The ability of prenatal choline supplementation to enhance CNS function and decrease vulnerability to neurotoxicity may have wide-ranging implications. For example, the age at which we first treated animals in this study (P39) is shortly after the onset of vulnerability to MK-801-induced neurotoxicity (Farber et al., 1995; Auer, 1996), and also is within the periadolescent period of development in rats (Odell, 1990; Witt, 1994). Thus, the present results have implications for adolescent health, in that it is during 


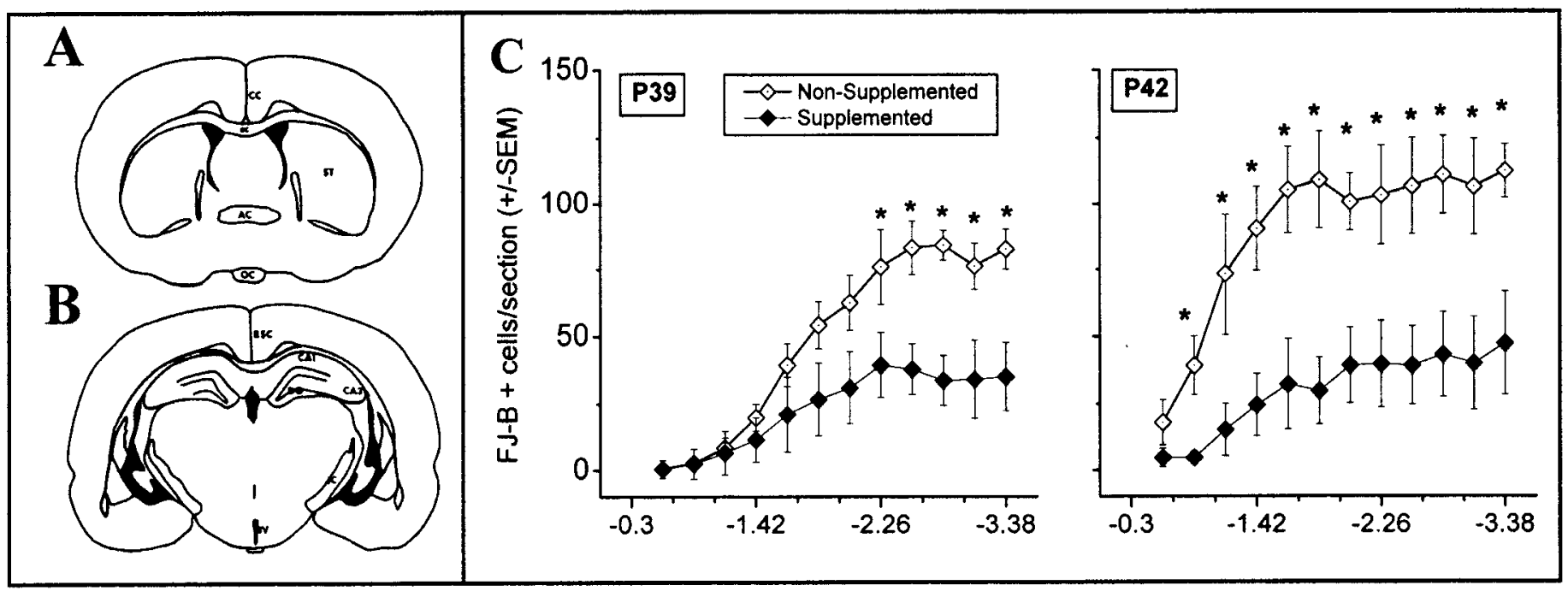

Figure 3. Protective effects of prenatal choline supplementation against MK-801-induced neurodegeneration in female offspring. A, Outline of a coronal section of the rat brain at the level of the optic chiasm (corresponding to $0.3 \mathrm{~mm}$ posterior to bregma). This is the anterior-most part of the CC at which counting of Fluoro-Jade-positive cells commenced. $A C$, Anterior commissure; $c c$, corpus callosum; OC, optic chiasm; ST, striatum. B, Outline of a coronal section of the rat brain at the level of the posterior-most part of the dorsal hippocampus (corresponding to $3.8 \mathrm{~mm}$ posterior to bregma). This is the posterior-most part of the cingulate cortex (the RSC) at which counting of Fluoro-Jade-positive cells ended. $D G$, Dentate gyrus; $3 \mathrm{~V}$, third ventricle; $I C$, internal capsule. $C$, Graphs show the number of Fluoro-Jade-B-positive $(F J-B+)$ neurons in the CC-RSC per section from female offspring treated with MK-801 on P39 (left) and P42 (right). Asterisks indicate a significant difference $(p<0.05$; SPSS Inc., Chicago, IL) between equivalent rostral-to-caudal sections from supplemented and nonsupplemented offspring. $x$-axis, Approximate coordinates relative to bregma (36); $y$-axis, mean FJ-B + neurons (bilaterally) in the CC-RSC, per section ( \pm SEM).

adolescence that many individuals initiate recreational use of a variety of psychoactive compounds, including NMDA receptor antagonists such as phencyclidine, ketamine, and alcohol. We also observed that the protective effect of prenatal choline supplementation was greater when MK-801 treatment was delayed several days later into adolescent development (P42). This is consistent with previous studies that have shown that the neurotoxicity of MK-801 increases with age into adulthood (Farber et al., 1995; Auer, 1996). It is not known whether the neuroprotective effect of prenatal choline supplementation persists into adulthood, but studies are currently underway in our laboratory to assess that possibility.

In addition to recreational use, NMDA receptor antagonists have been used clinically, although their use in humans has been curtailed because of unacceptable behavioral side effects. The present results suggest a possible approach toward enhancing resistance to NMDA receptor antagonist toxicity that could lead to strategies that would allow the safe therapeutic use of these compounds.

Perhaps even more intriguing is the possibility that prenatal dietary choline manipulation could decrease the vulnerability to some psychiatric illnesses. Converging lines of evidence suggest that the type of neuronal injury that occurs after exposure to NMDA receptor antagonists may be related to the onset or acute manifestation of psychosis (Ellison, 1995; Farber et al., 1995). Developmentally, the onset of psychotic schizophrenic symptoms in humans generally does not occur until adolescence or early adulthood (Rapoport et al., 1997), a developmental onset that is consistent with the onset of toxic liability to NMDA receptor antagonists in rats (Farber et al., 1995; Auer, 1996). In addition, abnormalities in both the cingulate gyrus (Shergill et al., 2000; Tamminga et al., 2000) and thalamic nuclei that modulate cingulate activity (Shergill et al., 2000; Sharp et al., 2001) have been implicated in the etiology of psychosis. Finally, drugs that ame- liorate or prevent psychotic symptoms, such as haloperidol and olanzapine, also attenuate NMDA receptor antagonist-induced neurotoxicity (Sharp et al., 1994; Farber et al., 1996). Thus, prenatal choline supplementation, as a treatment that protects against NMDA receptor antagonist-induced neurotoxicity, could potentially diminish the likelihood of psychosis in adolescents or young adults.

\section{REFERENCES}

Auer RN (1996) Effect of age and sex on $N$-methyl-D-aspartate antagonist-induced neuronal necrosis in rats. Stroke 27:743-746.

Belluardo N, Mudo G, Blum M, Fuxe K (2000) Central nicotinic receptors, neurotrophic factors, and neuroprotection. Behav Brain Res 113:21-34.

Blusztajn JK (1998) Choline, a vital amine. Science 281:794-795.

Cermak J, Holler T, Jackson D, Blusztajn JK (1998) Prenatal availability of choline modifies the development of the hippocampal cholinergic system. FASEB J 12:349-357.

Cermak JM, Blusztajn JK, Meck WH, Williams CL, Fitzgerald CM, Rosene DL, Loy R (1999) Prenatal availability of choline alters the development of acetylcholinesterase in the rat hippocampus. Dev Neurosci 21:94-104.

Corso TD, Sesma MA, Tenkova TI, Der TC, Wozniak DF, Farber NB, Olney JW (1997) Multifocal brain damage induced by phencyclidine is augmented by pilocarpine. Brain Res 752:1-14.

Ellison G (1995) The $N$-methyl-D-aspartate antagonists phencyclidine, ketamine, and dizocilpine as both behavioral and anatomical models of the dementias. Brain Res Brain Res Rev 20:250.

Farber NB, Wozniak DF, Price MT, Labruyere J, Huss J, St Peter H, Olney JW (1995) Age-specific neurotoxicity in the rat associated with NMDA receptor blockade: potential relevance to schizophrenia? Biol Psychiatry 38:788-796.

Farber NB, Foster J, Duhan NL, Olney JW (1996) Olanzapine and fluperlapine mimic clozapine in preventing MK-801 neurotoxicity. Schizophr Res 21:33-37.

Fix AS, Wozniak DF, Truex LL, McEwen M, Miller JP, Olney JW (1995) Quantitative analysis of factors influencing neuronal necrosis induced by MK-801 in the rat posterior cingulate/retrosplenial cortex. Brain Res 696:194-204.

Holler T, Cermak JM, Blusztajn JK (1996) Dietary choline supplementation in pregnant rats increases hippocampal phospholipase D activity of the offspring. FASEB J 10:1653-1659. 
Hönack D, Löscher W (1993) Sex differences in NMDA receptor mediated responses in rats. Brain Res 620:167-170.

Lauder JM, Schambra UB (1999) Morphogenetic roles of acetylcholine. Environ Health Perspect 107 [Suppl 1]:65-69.

Li Q, Clark S, Wilson WA, Lewis DV (2000) MK-801, an NMDA receptor antagonist, modulates the inhibitory postsynaptic currents in pyramidal neurons in the cingulate cortex of rats. Soc Neurosci Abstr 26:431.

Meck WH, Williams CL (1997) Characterization of the facilitative effects of perinatal choline supplementation on timing and temporal memory. NeuroReport 8:2831-2835.

Meck WH, Smith RA, Williams CL (1988) Pre- and postnatal choline supplementation produces long-term facilitation of spatial memory. Dev Psychobiol 21:339-353.

Montoya D, Swartzwelder HS (2000) Prenatal choline supplementation alters hippocampal $N$-methyl-D-aspartate receptor-mediated neurotransmission in adult rats. Neurosci Lett 296:85-88.

Odell W (1990) Sexual maturation in the rat. In: Control of the onset of puberty (Grumbach M, Sizonenko P, Aubert M, eds), pp 183-210. Baltimore: Williams and Wilkens.

Olney JW, Labruyere J, Price MT (1989) Pathological changes induced in cerebrocortical neurons by phencyclidine and related drugs. Science 244:13602.

Olney JW, Labruyere J, Wang G, Wozniak DF, Price MT, Sesma MA (1991) NMDA receptor antagonist neurotoxicity: mechanism and prevention. Science 254:15158.

Pyapali GK, Turner DA, Williams CL, Meck WH, Swartzwelder HS (1998) Prenatal dietary choline supplementation decreases threshold for induction of long-term potentiation in young adult rats. J Neurophysiol 79:1790-1796.

Rapoport JL, Giedd J, Kumra S, Jacobsen L, Smith A, Lee P, Nelson J, Hamburger S (1997) Childhood-onset schizophrenia: progressive ventricular change during adolescence. Arch Gen Psychiatry 54:897-903.

Schmued LC, Hopkins KJ (2000) Fluoro-Jade. Novel fluorochromes for detecting toxicant-induced neuronal degeneration. Toxicol Pathol 28:91-99.

Schmued LC, Albertson C, Slikker Jr W (1997) Fluoro-Jade: a novel fluorochrome for the sensitive and reliable histochemical localization of neuronal degeneration. Brain Res 751:37-46.

Sharp FR, Butman M, Aardalen K, Nickolenko J, Nakki R, Massa SM, Swanson RA, Sagar SM (1994) Neuronal injury produced by NMDA receptor antagonists can be detected using heat shock proteins and can be blocked with antipsychotics. Psychopharmacol Bull 30:555-560.

Sharp FR, Tomitaka M, Bernaudin M, Tomitaka S (2001) Psychosis: pathological activation of limbic thalamocortical circuits by psychomimetics and schizophrenia? Trends Neurosci 24:330-334.

Shergill SS, Brammer MJ, Williams SC, Murray RM, McGuire PK (2000) Mapping auditory hallucinations in schizophrenia using functional magnetic resonance imaging. Arch Gen Psychiatry 57:1033-1038.

Tamminga CA, Vogel M, Gao X, Lahti AC, Holcomb HH (2000) The limbic cortex in schizophrenia: focus on the anterior cingulate. Brain Res Brain Res Rev 31:364-370.

Tomitaka S, Tomitaka M, Tolliver BK, Sharp FR (2000) Bilateral blockade of NMDA receptors in anterior thalamus by dizocilpine (MK-801) injures pyramidal neurons in rat retrosplenial cortex. Eur J Neurosci 12:1420-1430.

Williams CL, Meck WH, Heyer DD, Loy R (1998) Hypertrophy of basal forebrain neurons and enhanced visuospatial memory in perinatally choline-supplemented rats. Brain Res 794:225-238.

Witt E (1994) Mechanisms of alcohol abuse and alcoholism in adolescents: a case for developing animal models. Behav Neural Biol 62:168-177.

Yang Y, Liu Z, Cermak JM, Tandon P, Sarkisian MR, Stafstrom CE, Neill JC, Blusztajn JK, Holmes GL (2000) Protective effects of prenatal choline supplementation on seizure-induced memory impairment. J Neurosci 20:RC109:1-6.

Zeisel SH, Blusztajn JK (1994) Choline and human nutrition. Annu Rev Nutr 14:269-296. 